\title{
Impact of Soluble Fiber in the Microbiome and Outcomes in Critically III Patients
}

\author{
Carla Venegas-Borsellino ${ }^{1} \cdot$ Minkyung Kwon $^{1,2}$ \\ Published online: 7 November 2019 \\ (C) Springer Science+Business Media, LLC, part of Springer Nature 2019
}

\begin{abstract}
Purpose of Review To discuss the controversy over the effect of dietary fiber (DF) on (1) outcomes in critical illness, (2) microbiome and metabolic homeostasis, and (3) current evidence and guidelines regarding supplementation in critically ill patients.

Recent Findings In healthy individuals, consumption of DF is widely known as a long-term protecting factor against colon cancer, cardiovascular disease, and other metabolic disorders like obesity, type 2 diabetes, and fatty liver disease; in hospitalized patients, DF may have a beneficial effect in the incidence of diarrhea, infections, and length of stay. But, what does that mean for critically ill patients? What is the recommended DF intake and what are current guidelines?

Summary There are many confounding factors that limit the evidence of beneficial effects from fiber supplementation in critically ill patients, including the side effects critical care therapies can have on gut microbiota, but after extrapolating data from healthy and hospitalized non-critical patients and considering that its administration appears to be safe, it may be wise to administer fiber-containing enteral feedings in ICU patients. Analysis of those confounders requires future research.
\end{abstract}

Keywords Dietary fiber $\cdot$ Critical illness $\cdot$ Microbiome $\cdot$ Inflammatory response $\cdot$ Small chain fatty acids

\section{Introduction}

Ingested fiber plays an important role in the complex milieu of gut microbiota homeostasis. [1] There is increasing interest in the relationship between the components of the microflora and its influence in diseases such as obesity, cardiovascular disease (CVD), dementia, and the acute and chronic inflammatory response seen in critical illness [2], as well as the role that fiber plays in sustaining healthy gut flora. [3•] While the positive effects of DF in healthy $[4,5]$ and hospitalized patients $[1,6]$ have been widely published, the critical care literature remains sparse. [4, 7-9]

Carla Venegas-Borsellino

Venegas-Borsellino.Carla@mayo.edu

1 Department of Critical Care Medicine, Mayo Clinic, 4500 San Pablo Road, Jacksonville, FL 32224, USA

2 Department of Pulmonary Medicine, Mayo Clinic, Jacksonville, FL 32224, USA
Dietary fiber, an essential component of the human diet, helps maintain the homeostasis of the gut microbiota by providing needed substrate to produce small chain fatty acids (SCFAs). [1] SCFAs are recognized for maintaining intestinal barrier integrity, decreasing the inflammatory response in the intestinal epithelium [2], and playing a role in immunomodulation and local gut homeostasis by suppressing pathogenic bacteria overgrowth and promoting growth of commensal microflora, like lactobacillus and bifidobacterial which together comprise more than $90 \%$ of microflora. $[2,8]$ There has been particular interest in determining the amount and kind of fiber and prebiotics provided in enteral formulas necessary to increase the level of SCFAs in the colon with positive results. [10] This has been difficult to assess in critically ill patients considering study populations' heterogeneity; etiology and severity of illness; pre-existing comorbidities and nutritional status; the influence of hemodynamics; and the frequent exposure to antibiotics. All these factors can negate the beneficial effects of fiber supplementation. [11]

The positive effects of DF in elevating colon SCFA concentrations observed in healthy populations and non-critically ill patients $[1,5,6]$ have not been clearly observed in the 
intensive care unit (ICU), where patients receiving fiberenriched enteral nutrition typically have low SCFA concentrations. $[8,9]$ Fiber-containing enteral feeding is still considered appropriate and safe for this high-risk population after extrapolating data from healthy and hospitalized non-critical patients.

\section{Understanding Basic Concepts}

There is no single definition that explains what DF is and where it is found [12]. The International Codex Alimentarius Commission [13] describes it as a chain of three or more monomeric carbohydrate units which cannot be digested or absorbed by the human small intestine [14] and pass intact into the colon where they are fermented or excreted, leaving no biological marker to track in serum. [15] These characteristics make it difficult to determine estimated average requirement (EAR) and recommended dietary allowance (RDA); current recommendations address adequate intake (AI), with calculations derived from studies focused on preventing CVD mortality [16].

Fiber is mainly found in plants and the importance of its consumption is related to its metabolic byproducts. When DF reaches the large intestine, it is fermented by intestinal bacteria into molecular hydrogen $\left(\mathrm{H}_{2}\right)$ and carbon dioxide $\left(\mathrm{CO}_{2}\right)$, which can be reduced to methane $\left(\mathrm{CH}_{4}\right)$, and SCFAsmainly acetic, propionic, and butyric acid (the most important due to its effect as an easy energy substrate for colonocytes) [17]. SCFAs play a crucial role in maintenance of the intestinal gut barrier and prevention of bacterial translocation by $[1,7$, $18,19]$

- Stimulating colonic blood flow

- Decreasing local $\mathrm{pH}$

- Promoting proliferation and differentiation of epithelial cells

- Maintaining local homeostasis

- Enhancing immunomodulation

- Suppressing pathogenic bacteria overgrowth

Commonly used classifications of fiber are based on the source, structure, or fermentation potentials [12, 15], but for dietary purposes, the most useful classification is based on water solubility [7, 12]: (1) insoluble fiber, like lignin and cellulose, is found in wheat bran and soy polysaccharide, and its function relates to laxation [7]; (2) water soluble fiber, like pectin, gum, and $\beta$-glycan, is precipitated by ethanol and is found in oat bran, barley bran, guar gum, inulin, and psyllium. The importance of soluble fiber is that it is completely fermented in the large bowel [7] with significant production of SCFAs [1], resulting in downstream related systemic health benefits like cardiovascular protection.

\section{Are Current Daily Fiber Intake Recommendations Appropriate?}

Recommended dietary reference intake (DRI) for DF is consumption of $25 \mathrm{~g}$ for adult women and $38 \mathrm{~g}$ for adult men, based on a $2000 \mathrm{kcal} /$ day diet [12], supported by epidemiologic studies showing protection against CVD, but not addressing the necessary dose to reach anti-inflammatory or antineoplastic effects found in a higher daily consumption (above $50 \mathrm{~g} /$ day). [20] This higher fiber intake requirement appears to be related to the amount needed to produce optimal levels of butyrate in the luminal mucosa. Unfortunately, the typical American diet only provides an average daily intake of $\sim 15 \mathrm{~g} /$ day [21] due to a diet rich in processed food and poor in whole foods, fruits, and vegetables.

There is no significant literature to support specific recommendations in high-risk populations like children, the elderly, hospitalized patients, and the critically ill, so in these groups, current recommendations are still based on daily energy intake. For hospitalized patients receiving enteral nutritional (EN) support via tube feeding, the daily consumption is even more inadequate due to the low amount of soluble fiber per liter typically available in current formulas.

Defining normal daily fiber requirements is particularly challenging for critically ill patients, whose fiber consumption is greatly affected by the fiber-depleted formulas used at trophic goals, likely promoting more dysbiosis and a persistent inflammatory response. [4]

\section{What About the Amount and Kind of Dietary Fiber Supplemented in Enteral Nutrition?}

Enteral formulas have evolved over the years to accommodate patients' needs. Early on, they lacked a fiber component due to fears of causing bowel obstruction. [3•] Fortunately, growing evidence regarding benefits of fiber, such as enhanced immunomodulatory gut function, positive effect in serum lipid and glucose regulation [22], and others, have allowed its introduction in modern available formulas.

Fiber-enriched enteral formulas are commonly supplemented with purified fiber of a single source like soy polysaccharide or mixed fiber composed of partially hydrolyzed guar gum, psyllium, oat, pea, inulin, banana flakes, galactomannan, and sugar beet fibers. [3•] Other formulas use fructooligosaccharides (FOS), non-digestible short-chain oligosaccharides, which are easily fermented into SCFAs. As FOSs are not degraded by pathogenic bacteriae they are a great substrate for bifidobacteria and help maintain homeostasis at the microbiota level. Dosages given in ICU populations average from 5 to $39 \mathrm{~g} /$ day $[3 \cdot, 23]$.

Unfortunately, critically ill patients who frequently require EN support by tube feeding are exposed to multiple factors 
that disrupt microbiota homeostasis: (1) They are frequently underfed with trophic feeds for days; (2) They are supported only with elemental formulas containing poor amounts of dietary fiber $(\sim 4 \mathrm{~g} / \mathrm{L})$; (3) The majority of these patients are exposed to broad-spectrum antibiotics; and (4) Hemodynamic instability and use of vasopressors predispose them to bowel hypoperfusion and ischemia. All these factors contribute to the low luminal SCFA concentrations found in critically ill patients when compared to healthy individuals, which causes colon starvation and favors the overgrowth of pathologic microorganisms at the expense of normal fecal microbial communities. [9, 24] Regrettably, one study found that fiberenriched EN given to critically ill patients failed to increase SCFA concentrations. [18]

Although there is still no evidence of fiber addressing this low SCFA issue, it is necessary to consider DF supplementation in critically ill patients due to its potential for restoring bowel function, prevention of diarrhea [25] and bacterial translocation, and the improved prognoses seen in general hospitalized patients and some ICU studies. [26••]

\section{How Can Dietary Fiber Reduce the Inflammatory Response?}

The colonic mucosa is a unique place where there is a constant symbiotic equilibrium essential for the survival and health of the local epithelium, with important consequent systemic effects. A high-fiber diet results in higher levels of SCFAs after fermentation, and selectively favors the growth of commensal degraders such as Bifidobacteriums, which produce lactate and reduce luminal $\mathrm{pH}$, which further promotes growth of other butyrate producers, and, most importantly, suppresses overgrowth of pathogens. [4] These reactions favor the positive effect of butyrate in maintaining mucosal integrity and immunomodulation via stimulation of regulatory $\mathrm{T}$ cells, the promotion of a balanced microbial metabolism, and modulation of inflammation and epithelial proliferation. The butyrate effect also plays an important role in suppressing long-term risk of carcinogens. [2]

During the metabolism of fiber in the colon, there is also release of phytocomponents with important anti-inflammatory and antineoplastic characteristics. Other protective effects provided from a well-balanced microbiota include the production of B-complex vitamins like B12, B7, B3, and B9, some of them only produced by local bacteria. [27]

Diets rich in meat and fat result in increased sulfur and hydrogen sulfide production which perpetuates local inflammation in the colon and generates well-described carcinogens like taurine (a conjugated bile acid with high sulfur content). [4, 28, 29] High protein diets induce proteolytic fermentation in the microbiota which releases other pro-inflammatory and pro-neoplastic metabolites like phenolic, p-cresol, and nitrosamines. [30] In contrast, diets with high soluble and insoluble fiber content have a protective effect over those aggressors. [31]

Currently, there is more understanding regarding the gut interaction with hepatic steatosis, steatohepatitis, the systemic inflammatory response, and the consequent multi-organ failure seen in ICU patients, linked through the increased mucosa permeability, release of endotoxin, activation of NF-kB, and pro-inflammatory cytokines. [2, 32] Table 1 refers to other studies evaluating the efficacy of dietary fiber in acute inflammatory conditions.

\section{Has Dietary Fiber Shown Positive Effects in Critical Illness?}

Limitations to demonstrating the effect of DF in the critically ill include the brief intervention during the ICU stay, lack of appropriately defined end-point goals in critical illness, difficulties in measuring long-term outcomes, and the fact that ICU populations who may receive the greatest benefit, like the hemodynamically unstable with severe inflammatory response, are usually excluded from the studies. It is also difficult to correlate outcomes, as stool markers of dietary fiber and SCFAs are rarely measured and blood levels are not available. The most frequently measured benefits of using DF in enteral formulas are the effects on diarrhea, infection, and length of hospital stay, with significant variability in available results.

Diarrhea Patients receiving EN often present with diarrhea related to altered gut motility, impaired barrier integrity, or factors related to the nutritional formula per se (type, osmolality, dosage, amount of fiber). [42] Diarrhea in critically ill patients receiving EN is frequent (up to $70 \%$ of patients) and higher than in noncritical cohorts. $[3 \cdot, 7,43]$ According to the severity of the diarrhea, major consequences can be seen, from electrolyte disturbances and dehydration, to decrease (wipe out) of the commensal microbiota [44], so interest to ascertain whether supplemental fiber in $\mathrm{EN}$ can improve diarrhea has been growing.

Administration of soluble fibers can increase fecal SCFA concentrations [45] and have an antidiarrheal effect [25] by increasing water and electrolyte uptake [46] even in critically ill patients receiving antibiotics [42], but results vary among different authors (see Table 2). Although large meta-analyses report reduction of diarrhea in non-critically ill patients receiving fiberenriched EN [3•, 25], those effects have not been consistently observed in critically ill patients. Multiple metaanalyses indicate that soluble fibers could significantly reduce episodes of diarrhea in the general population, especially at intake doses higher than $30 \mathrm{~g} /$ day [25], but not in patients under intensive care [3•], who usually receive less than $12 \mathrm{~g}$ per day. [7] 
Table 1 Effect of dietary fiber and symbiotics in different acute conditions

\begin{tabular}{|c|c|c|}
\hline Conditions & Component & Effect of fiber/symbiotic \\
\hline Ulcerative colitis & $\begin{array}{l}\text { Symbiotic }(12 \mathrm{~g} / \text { day of } \\
\text { inulin-oligofructose })\end{array}$ & $\begin{array}{l}\text { Reduces tissue inflammation and inflammatory cytokines [33], } \\
\text { anti-inflammatory or chemo-preventive effect }\end{array}$ \\
\hline $\begin{array}{l}\text { Post-colectomy/colonic } \\
\text { polypectomy }\end{array}$ & Symbiotic (oligofructose) & Increases anti-inflammatory cytokines [34] \\
\hline $\begin{array}{l}\text { Post colonic } \\
\text { polypectomy }\end{array}$ & Symbiotic (oligofructose and inulin) & $\begin{array}{l}\text { Increases Bifidobacterium and Lactobacillus, and decreases Clostridium } \\
\text { perfringens }[35]\end{array}$ \\
\hline Critical illness & Symbiotic supplementation (oligofructose) & Lowers potentially pathogenic bacteria from gastric aspirate [36] \\
\hline $\begin{array}{l}\text { Burn patients } \\
\quad \text { (guidelines) }\end{array}$ & & $\begin{array}{l}\text { There are recommendations for supplement high-doses of selenium, } \\
\text { zinc and copper, fat-soluble and water-soluble vitamins, but there are } \\
\text { no specific recommendations on fiber supplementation [37] }\end{array}$ \\
\hline Liver transplant & $\begin{array}{l}\text { Symbiotic (one lactic acid bacteria and } \\
\text { one fiber) }\end{array}$ & Reduction of post-op bacterial infection in fiber group [38] \\
\hline Abdominal surgery & Fiber and lactobacillus & Reduction of postoperative infection in fiber group [38] \\
\hline Acute pancreatitis & Oat fiber and lactobacillus & $\begin{array}{l}\text { Lower rate of infected pancreatic necrosis and abscess in treatment } \\
\text { group [39] }\end{array}$ \\
\hline Acute pancreatitis & $\begin{array}{l}\text { Probiotic with fiber-enriched formula } \\
\text { (Nutrison Multifiber) }\end{array}$ & More deaths in study group [40] \\
\hline $\begin{array}{l}\text { Critically ill patients } \\
\text { (meta-analysis) }\end{array}$ & Symbiotics & Limited data for symbiotics compared to probiotics $[26 \bullet \bullet]$ \\
\hline Acute pancreatitis & Symbiotics & Did not reduce the risk of infection [40] \\
\hline Trauma & $\begin{array}{l}\text { Fermentable fiber and Symbiotic } \\
\quad \text { (lactobacilli and bioactive fibers) }\end{array}$ & Lower rate of infection in symbiotic group [41] \\
\hline
\end{tabular}

Infection and Immunological Support Enteral feeding induces intestinal transit changes that influence the secretory mechanisms and, as mentioned, impact the microbiota homeostasis. [10] It is unclear if these changes are associated with intestinal bacterial translocation and increased risk of infection in critically ill populations. Studies have focused on determining if supplemental DF can improve outcomes by preserving the tight junctions and epithelium structure, stimulating the Tlymphocytes response, and increasing the secretion of $\operatorname{IgA}$, without positive results. [17]

Length of Stay: Enteral nutrition supplemented with DF versus standard enteral formula has shown significant reductions in length of hospital stay by 1-3 days in postoperative patients who have undergone liver transplantation or abdominal surgery. [17]

Dietary Fiber and Its Effect in Metabolism Studies on consumption of soluble and insoluble fiber (favoring the former) have shown positive effects on glucose metabolism [14], possibly by slowing the rate of nutrient absorption [49], raising oxidation rate of glucose and insulin clearance, and decreasing the release of fatty acids.[50] Soluble fiber ingestion can rapidly reduce the insulin response by $40 \%$ and blood sugar levels by up to $60 \%$ [51]; a post-prandial delayed effect has also been described. [40] No effects have been seen in body weight, cholesterol, or electrolyte balance. [14]

Effect on Microbiota Depending on the type of fiber used to supplement the enteral formula, results have been variable with respect to the success of achieving higher SCFA concentrations resulting in enhanced microbiota composition, some showing an increased effect [1], others unchanged. [1, 6, 8, 52] Administration of a prebiotics and mixed fiber enriched formula led to an increase in total number but not a restoration of healthy heterogeneity in bacterial populations [1]; supplementation with galactomannan [6] resulted in a decrease in aerobic bacteria, but in general, there were no reports of changes in fecal bifidobacteria concentrations. $[1,8,52]$

These inconsistent observations in critical illness are likely multifactorial yet related to factors associated with the care provided in the ICU (such as use of broad-spectrum antibiotics, opioids, vasopressors, and gastric acid suppression therapy) that impair microbiota homeostasis and SCFA concentrations and reduces microbial counts by more than $90 \%$, especially butyrate producers and starch degraders, as soon as within $6 \mathrm{~h}$ after ICU admission. [24] Increasing doses of fiber supplementation in ICU patients up to $36 \mathrm{~g}$ has been shown to be safe and well-tolerated, with some (but not complete) recovery of the colonic microbiota. [49]

\section{Prebiotics, Probiotics, or Symbiotics: Does It Matter?}

Prebiotics, probiotics, and symbiotics are provided to stimulate colonic SCFA production. Prebiotics, non-digestible fibrous carbohydrates, act like fuel for gut microbiota and serve 
Table 2 Studies looking at efficacy of dietary fibers for reduction of diarrhea in adult critically ill patients

\begin{tabular}{|c|c|c|}
\hline Population & Component & Effect of fiber \\
\hline $\begin{array}{l}\text { Severe sepsis and septic } \\
\text { shock on mechanical } \\
\text { ventilation }\end{array}$ & Partially hydrolyzed guar & $\begin{array}{l}\text { Days with diarrhea were significantly lower in fiber group (reduced } \\
\text { at least by } 1 \text { day). [47] }\end{array}$ \\
\hline $\begin{array}{l}\text { ICU patients on mechanical } \\
\text { ventilation }\end{array}$ & $\begin{array}{l}\text { Soy polysaccharides, Arabic gum, inulin, } \\
\text { alpha-cellulose, oligofructose, resistant starch }\end{array}$ & $\begin{array}{l}\text { Significant difference in diarrhea episodes and lower diarrhea scores } \\
\text { in the last three days }(p<0.01) \text { in the fiber receiving group. [48] }\end{array}$ \\
\hline Surgical ICU septic patients & Mixed fiber formulas & $\begin{array}{l}\text { Mean diarrhea scores were significantly lower in fiber group after } 14 \\
\text { days of treatment. [46] }\end{array}$ \\
\hline Necrotizing pancreatitis & $\begin{array}{l}\text { Wheat dextrin with progressive supplementation } \\
\text { of } 18 \mathrm{~g}, 24 \mathrm{~g} \text {, and } 36 \mathrm{~g} \text { over } 5 \text { weeks of } \\
\text { treatment. }\end{array}$ & Diarrhea improved in 3 out of 4 patients, no complications. [49] \\
\hline $\begin{array}{l}\text { ICU patients with high } \\
\text { APACHE II score 16-22 }\end{array}$ & Soluble fiber $22 \mathrm{~g} / 1000 \mathrm{ml}$ feed & Reduction of diarrhea by day 4 [23] \\
\hline $\begin{array}{l}\text { Critically ill patients } \\
\text { (meta-analysis) }\end{array}$ & $\begin{array}{l}\text { Enteral nutrition with dietary fibers in various } \\
\text { formula }\end{array}$ & No statistically significant effect on diarrhea reduction [17] \\
\hline
\end{tabular}

as a substrate for probiotics, which are living microorganisms having protective effects in maintaining the gut barrier. Most commercial probiotics are various strains of Bifidobacterium or Lactobacillus. A symbiotic is a mixed formula with both prebiotics and probiotics. $[50,51]$

One or more strains of prebiotics can be administered to obtain an additive immune-stimulant benefit and reinforce gut integrity. In addition to being a substrate for SCFA producers, prebiotics have been associated with activation of the GALT system (gut-associated lymphoid tissue), stimulation of Peyer's patches, and acidification of the intestinal lumen. [53] Studies conducted in healthy populations have shown that $10 \mathrm{~g}$ of prebiotics (mainly FOS, oligofructose, and inulin) can increase SCFAs and bifidobacteria concentration [54], reduce diarrhea [15] and clostridia in stool. [10] In patients with Clostridium difficile-associated diarrhea, reduction on relapses has been reported. [55]. Such positive effects, however, have not been consistently seen in hospitalized patients $[3 \bullet, 8]$ who may need higher doses to obtain similar results.

The use of probiotics in critically ill patients has been more controversial due to early studies suggesting a significant increase in mortality when used in patients with severe acute pancreatitis [40] and case reports of septicemia in severely immunocompromised hosts (without reported mortalities). $[56,57]$ More recent literature have shown the following positive effects, among many others: attenuation of pathogen overgrowth, decreased bacterial translocation by suppressing abnormal cell proliferation, enhanced $\operatorname{IgA}$ production, and a protective effect against viruses. [53] While these protective effects appear to have an impact in infections, the use of probiotics in critically ill patients remains controversial due to difficulties in providing conclusive proof in this population.

The most recent and largest meta-analysis of probiotics in critical illness, published in 2016, included 30 randomized control trials (RTCs) with almost 3000 ICU patients, showed a significant protective effect on ventilator associated pneumonia (VAP); but no statistical difference in overall hospital and ICU mortality, hospital or ICU length of stay, or effect on diarrhea, although they found that patients who received probiotics had reduced duration of antibiotic therapy. Importantly, in terms of safety, this analysis found no changes in complications from infection, even at high dose probiotics. [26••]

Symbiotics were developed to obtain the synergistic effects of combining prebiotics and probiotics for a maximal immunoregulatory response. Reported benefits include a decrease in oxidative stress and neutrophil infiltration, which are considered responsible for multiple endothelial cell injuries, capillary leakage and the consequent severe pulmonary dysfunction found in acute respiratory distress syndrome (ARDS) and multi-organ failure (MODS). Experimental studies suggest that neutrophilic pulmonary infiltration can be prevented by the enteral administration of symbiotics, which could be a key in inhibiting the acute inflammatory response seen in critical illness, but clinical studies remain inconclusive. [15]

Early literature suggests that using symbiotics may be more effective in restoring the intestinal microbiota compared with probiotics alone, [58] but controversies around the effect on clinic outcomes remain. [26••, 59] Inconsistent results could be related to the types and amounts of strains used, and the various prepared combinations. [60] The use of Synbiotic2000 in post liver transplant patients (for 14 days) led to a decreased incidence of both postoperative bacterial infections and total use of antibiotics. [38, 61] The same preparation given to critically ill patients showed increased levels of Lactobacillus colonies in the feces and a reduced incidence of VAP in mechanically ventilated patients, without effects on duration of mechanical ventilation, mortality, or ICU length of stay. [60] Sub-analysis of a recent large meta-analysis reported no effect on reducing the incidence of infections with symbiotics use [26••]; and when use of probiotic vs symbiotic were compared, there was no statistical difference. 
Historically, there has been concern with the use of symbiotics in pancreatitis after the probiotic prophylaxis in patients with predicted severe acute pancreatitis (POPATRIA) trial reported higher mortality and bowel ischemia with post-pyloric administration of a symbiotic combination $[62,63]$. However, modern studies [26**] and a safety evaluation of about 600 trials (American Health Care Research and Quality (AHRQ)) have proven safety with no significant increase of adverse events. [64]

\section{Safety Issues Around Use of Dietary Fiber in Critical Illness}

Accurately calculating individualized DF daily intake requirements based on bowel function remains a challenge. Side effects from its consumption within the current recommended ranges are unlikely, but excessive intake, especially in high risk populations, may induce poor water and micronutrient absorption. Mineral and vitamin malabsorption associated with diarrhea due to excessive intake have been reported. [65]

Commonly reported side effects of abdominal distention and flatulence are expected due to gas production from the fermentation of DF by anaerobic bacteria. It is recommended to slowly increase the dose of DF and water intake to avoid this inconvenient effect. There is increased risk of blockage in Dobhoffs and other small-bore feeding tubes in patients receiving enteral formulas enriched with gums and viscous fiber, so routine water flushes are recommended.

Isolated reports of poor outcomes have been published in patients with underlying colonic inertia or luminal obstruction. One of the most serious cases was a patient who developed mesenteric ischemia from a cecal bezoar while receiving intestinal motility suppressing medications at the same time as fiber supplemented enteral nutrition. [66] Another case involved a patient who developed a pharmacobezoar esophageal obstruction in the setting of underlying esophageal webs while taking an over-the-counter diet aid containing glucomannan, due to the high water absorbing capacity of this soluble fiber. [67]

Other significant reported outcomes for ICU patients who received DF supplementation include

1. When effect on gastric emptying was compared: (1) no effect on gastric residual volume was seen in supplemented verses control group [48] and (2) increased gastric residues were found in the diet intervention group. [63]

When fiber supplementation versus symbiotic versus control group were compared, there was no difference in gastric emptying. [41]

2. No difference in gastric intolerance and vomiting when fiber-supplemented formulas are used. [3•, 10, 48]
3. There are contradictory results regarding clinical differences in abdominal distension; some studies show no difference [49, 68], others report increased distention. [48]

4. Rates of constipation vary among studies, from significantly decreased in some treated groups [63], to no significant difference in others. [48]

As recommendations based-on-conclusive evidence are lacking, especially in hospitalized and critically ill patients, the foundations of current recommendations, evidence of side effects, or predictability of outcomes are not as solid as we would like.

\section{Guideline Recommendations}

There is limited literature supporting evidence-based recommendations regarding the questions of when, what, how much, and in whom, supplementation of DF is appropriate for hospitalized and critically ill patients. Generally speaking, DF can be tolerated well by patients with normal gastrointestinal tracts and can play a regulatory role in patients with constipation or diarrhea. For long-term patients, evidence from outpatient studies indicates that dietary fiber may have a strong metabolic immunomodulatory effect in chronic inflammatory diseases and the use of fiber-enriched enteral formula as part of their nutritional regimen is advisable. In critically ill patients, the small number of available studies seems to indicate at least safety in this high-risk population.

The most recent recommendations by the American Society for Parenteral and Enteral Nutrition (ASPEN), in conjunction with the Society of Critical Care Medicine (SCCM) in 2016 [69], are limited to (1) provide soluble fiber for hemodynamically stable critical patients who develop diarrhea, (2) recommend against the use of insoluble fiber, and (3) avoid any type of fiber in patients with severe motility impairment and high risk for mesenteric ischemia. This is in contrast with current recommendations by international societies like the Canadian Society-2003 [70] and the European Society for Clinical Nutrition and Metabolism (ESPEN) 2006 and its recently updated 2019 recommendations [71, 72] which did not include the topic due to limited available evidence for making any recommendation.

\section{Conclusion}

Dietary fiber intake has been associated with improvement in glucose and lipid metabolism and lower risk of chronic inflammatory processes in healthy populations. In hospitalized patients, it improves diarrhea, preserves microbiota by increasing SCFAs levels, and decreases hospital length of stay in certain populations. Statistically significant proof of 
benefits for critically ill patients is lacking, but dietary fiber supplementation appears to be safe, without detrimental impact on gastrointestinal symptoms like diarrhea, constipation, and gastric intolerance and vomiting.

Hindrances to inducing proven positive effects by supplementing dietary fiber in critically ill patients include the heterogeneity of the population, intestinal hypoperfusion frequently seen in critical illness, and the multiple therapies implemented in critical care. These factors ultimately alter the fine balance of intestinal flora required to maintain a healthy gut microbiota. Higher doses of soluble fiber may be needed to effectively repair/reverse the microbial disturbance. Further studies in optimal type, dose, and length of treatment of supplemental DF in critical illness are needed.

\section{Compliance with Ethical Standards}

Conflict of Interest Carla Venegas-Borsellino and Minkyung Kwon declare they have no conflict of interest.

Human and Animal Rights and Informed Consent This article does not contain any studies with human or animal subjects performed by any of the authors.

\section{References}

Papers of particular interest, published recently, have been highlighted as:

- Of importance

-• Of major importance

1. Schneider SM, Girard-Pipau F, Anty R, van der Linde EG, PhilipsenGeerling BJ, Knol J, et al. Effects of total enteral nutrition supplemented with a multi-fibre mix on faecal short-chain fatty acids and microbiota. Clin Nutr. 2006;25(1):82-90. https://doi.org/10.1016/j.clnu.2005.09.006.

2. Frazier TH, DiBaise JK, McClain CJ. Gut microbiota, intestinal permeability, obesity-induced inflammation, and liver injury. JPEN J Parenter Enteral Nutr. 2011;35(5 Suppl):14s-20s. https://doi.org/ 10.1177/0148607111413772.

3. Kamarul Zaman M, Chin KF, Rai V, Majid HA. Fiber and prebiotic supplementation in enteral nutrition: A systematic review and metaanalysis. World J Gastroenterol. 2015;21(17):5372-81. https://doi. org/10.3748/wjg.v21.i17.5372. Large recent meta-analyses in non-critically ill patients receiving fiber-enriched $\mathbf{E N}$.

4. O'Keefe SJD. The Need to Reassess Dietary Fiber Requirements in Healthy and Critically Ill Patients. Gastroenterol Clin N Am. 2018;47(1):219-29. https://doi.org/10.1016/j.gtc.2017.10.005.

5. Tarini J, Wolever TM. The fermentable fibre inulin increases postprandial serum short-chain fatty acids and reduces free-fatty acids and ghrelin in healthy subjects. Appl Physiol Nutr Metab. 2010;35(1):9-16. https://doi.org/10.1139/h09-119.

6. Nakao M, Ogura Y, Satake S, Ito I, Iguchi A, Takagi K, et al. Usefulness of soluble dietary fiber for the treatment of diarrhea during enteral nutrition in elderly patients. Nutrition. 2002;18(1):35-9.

7. Reis AMD, Fruchtenicht AV, Loss SH, Moreira LF. Use of dietary fibers in enteral nutrition of critically ill patients: a systematic review. Rev Bras Ter Intensiva. 2018;30(3):358-65. https://doi.org/10.5935/ 0103-507x.20180050.
8. Majid HA, Cole J, Emery PW, Whelan K. Additional oligofructose/ inulin does not increase faecal bifidobacteria in critically ill patients receiving enteral nutrition: a randomised controlled trial. Clin Nutr. 2014;33(6):966-72. https://doi.org/10.1016/j.clnu.2013.11.008.

9. Yamada T, Shimizu K, Ogura H, Asahara T, Nomoto K, Yamakawa $\mathrm{K}$, et al. Rapid and Sustained Long-Term Decrease of Fecal ShortChain Fatty Acids in Critically Ill Patients With Systemic Inflammatory Response Syndrome. JPEN J Parenter Enteral Nutr. 2015;39(5):569-77. https://doi.org/10.1177/0148607114529596.

10. Whelan K, Judd PA, Preedy VR, Simmering R, Jann A, Taylor MA. Fructooligosaccharides and fiber partially prevent the alterations in fecal microbiota and short-chain fatty acid concentrations caused by standard enteral formula in healthy humans. J Nutr. 2005;135(8): 1896-902. https://doi.org/10.1093/jn/135.8.1896.

11. Hill LT, Kidson SH, Michell WL. Corticotropin-releasing factor: a possible key to gut dysfunction in the critically ill. Nutrition. 2013;29(7-8):948-52. https://doi.org/10.1016/j.nut.2012.12.023.

12. Kuo SM. The interplay between fiber and the intestinal microbiome in the inflammatory response. Adv Nutr. 2013;4(1):16-28. https:// doi.org/10.3945/an.112.003046.

13. Howlett JF, Betteridge VA, Champ M, Craig SA, Meheust A, Jones JM. The definition of dietary fiber - discussions at the Ninth Vahouny Fiber Symposium: building scientific agreement. Food Nutr Res. 2010;54. doi:https://doi.org/10.3402/fnr.v54i0.5750.

14. Smith CE, Tucker KL. Health benefits of cereal fibre: a review of clinical trials. Nutr Res Rev. 2011;24(1):118-31. https://doi.org/10. 1017/s0954422411000023.

15. Verspreet J, Damen B, Broekaert WF, Verbeke K, Delcour JA, Courtin CM. A Critical Look at Prebiotics Within the Dietary Fiber Concept. Annu Rev Food Sci Technol. 2016;7:167-90. https://doi.org/10.1146/annurev-food-081315-032749.

16. Trumbo P, Schlicker S, Yates AA, Poos M. Dietary reference intakes for energy, carbohydrate, fiber, fat, fatty acids, cholesterol, protein and amino acids. J Am Diet Assoc. 2002;102(11):1621-30.

17. Yang G, Wu XT, Zhou Y, Wang YL. Application of dietary fiber in clinical enteral nutrition: a meta-analysis of randomized controlled trials. World J Gastroenterol. 2005;11(25):3935-8.

18. Gomez Candela C, de Cos Blanco AI, Iglesias Rosado C. Fiber and enteral nutrition. Nutr Hosp. 2002;17(Suppl 2):30-40.

19. Hylemon PB, Harris SC, Ridlon JM. Metabolism of hydrogen gases and bile acids in the gut microbiome. FEBS Lett. 2018;592(12): 2070-82. https://doi.org/10.1002/1873-3468.13064.

20. O'Keefe SJ. Diet, microorganisms and their metabolites, and colon cancer. Nat Rev Gastroenterol Hepatol. 2016;13(12):691-706. https://doi.org/10.1038/nrgastro.2016.165.

21. Slavin JL. Position of the American Dietetic Association: health implications of dietary fiber. J Am Diet Assoc. 2008;108(10): 1716-31.

22. Slavin J. Fiber and prebiotics: mechanisms and health benefits. Nutrients. 2013;5(4):1417-35. https://doi.org/10.3390/nu5041417.

23. Rushdi TA, Pichard C, Khater YH. Control of diarrhea by fiberenriched diet in ICU patients on enteral nutrition: a prospective randomized controlled trial. Clin Nutr. 2004;23(6):1344-52. https://doi.org/10.1016/j.clnu.2004.04.008.

24. Zaborin A, Smith D, Garfield K, Quensen J, Shakhsheer B, Kade $\mathrm{M}$, et al. Membership and behavior of ultra-low-diversity pathogen communities present in the gut of humans during prolonged critical illness. MBio. 2014;5(5):e01361-14. https://doi.org/10.1128/ mBio.01361-14.

25. Elia M, Engfer MB, Green CJ, Silk DB. Systematic review and meta-analysis: the clinical and physiological effects of fibrecontaining enteral formulae. Aliment Pharmacol Ther. 2008;27(2): 120-45. https://doi.org/10.1111/j.1365-2036.2007.03544.x.

26.• Manzanares W, Lemieux M, Langlois PL, Wischmeyer PE. Probiotic and synbiotic therapy in critical illness: a systematic review and meta-analysis. Crit Care. 2016;19:262. https://doi.org/10. 
1186/s13054-016-1434-y. The most recent and largest metaanalysis of probiotics in critical illness which includes 30 randomized control trials (RTCs) with almost 3000 ICU patients.

27. Gorbach SL. Microbiology of the Gastrointestinal Tract. In: Gorbach BS. Microbiology of the Gastrointestinal Tract. Medical Microbiology. Galveston (TX): University of Texas Medical Branch at Galveston; 1996.

28. Devkota S, Wang Y, Musch MW, Leone V, Fehlner-Peach H, Nadimpalli A, et al. Dietary-fat-induced taurocholic acid promotes pathobiont expansion and colitis in I110-/- mice. Nature. 2012;487(7405):104-8. https://doi.org/10.1038/nature11225.

29. Attene-Ramos MS, Wagner ED, Plewa MJ, Gaskins HR. Evidence that hydrogen sulfide is a genotoxic agent. Mol Cancer Res. 2006;4(1):9-14. https://doi.org/10.1158/1541-7786.mcr-05-0126.

30. Windey K, De Preter V, Verbeke K. Relevance of protein fermentation to gut health. Mol Nutr Food Res. 2012;56(1):184-96. https://doi.org/10.1002/mnfr.201100542.

31. Humphreys KJ, Conlon MA, Young GP, Topping DL, Hu Y, Winter $\mathrm{JM}$, et al. Dietary manipulation of oncogenic microRNA expression in human rectal mucosa: a randomized trial. Cancer Prev Res (Phila). 2014;7(8):786-95. https://doi.org/10.1158/1940-6207. capr-14-0053.

32. Liu T, Li J, Liu Y, Xiao N, Suo H, Xie K, et al. Short-chain fatty acids suppress lipopolysaccharide-induced production of nitric oxide and proinflammatory cytokines through inhibition of NFkappaB pathway in RAW264.7 cells. Inflammation. 2012;35(5): 1676-84. https://doi.org/10.1007/s10753-012-9484-z.

33. Furrie E, Macfarlane S, Kennedy A, Cummings JH, Walsh SV, O'Neil DA, et al. Synbiotic therapy (Bifidobacterium longum/ Synergy 1) initiates resolution of inflammation in patients with active ulcerative colitis: a randomised controlled pilot trial. Gut. 2005;54(2):242-9. https://doi.org/10.1136/gut.2004.044834

34. Roller M, Clune Y, Collins K, Rechkemmer G, Watzl B. Consumption of prebiotic inulin enriched with oligofructose in combination with the probiotics Lactobacillus rhamnosus and Bifidobacterium lactis has minor effects on selected immune parameters in polypectomised and colon cancer patients. Br J Nutr. 2007;97(4):676-84. https://doi.org/10.1017/S0007114507450292.

35. Rafter J, Bennett M, Caderni G, Clune Y, Hughes R, Karlsson PC, et al. Dietary synbiotics reduce cancer risk factors in polypectomized and colon cancer patients. Am J Clin Nutr. 2007;85(2):488-96. https://doi.org/10.1093/ajcn/85.2.488.

36. Jain PK, McNaught CE, Anderson AD, MacFie J, Mitchell CJ. Influence of synbiotic containing Lactobacillus acidophilus La5, Bifidobacterium lactis Bb 12, Streptococcus thermophilus, Lactobacillus bulgaricus and oligofructose on gut barrier function and sepsis in critically ill patients: a randomised controlled trial. Clin Nutr. 2004;23(4):467-75. https://doi.org/10.1016/j.clnu.2003. 12.002 .

37. de Garcia Lorenzo y Mateos A, Ortiz Leyba C, Sanchez SM. Guidelines for specialized nutritional and metabolic support in the critically-ill patient: update. Consensus SEMICYUC-SENPE: critically-ill burnt patient. Nutr Hosp. 2011;26(Suppl 2):59-62. https://doi.org/10.1590/s0212-16112011000800013.

38. Rayes N, Seehofer D, Theruvath T, Schiller RA, Langrehr JM, Jonas S, et al. Supply of pre- and probiotics reduces bacterial infection rates after liver transplantation-a randomized, double-blind trial. Am J Transplant. 2005;5(1):125-30. https://doi.org/10.1111/ j.1600-6143.2004.00649.x.

39. Olah A, Belagyi T, Poto L, Romics L Jr, Bengmark S. Synbiotic control of inflammation and infection in severe acute pancreatitis: a prospective, randomized, double blind study. Hepatogastroenterology. 2007;54(74):590-4.

40. Besselink MG, van Santvoort HC, Buskens E, Boermeester MA, van Goor H, Timmerman HM, et al. Probiotic prophylaxis in predicted severe acute pancreatitis: a randomised, double-blind, placebo-controlled trial. Lancet. 2008;371(9613):651-9. https:// doi.org/10.1016/s0140-6736(08)60207-x.

41. Spindler-Vesel A, Bengmark S, Vovk I, Cerovic O, Kompan L. Synbiotics, prebiotics, glutamine, or peptide in early enteral nutrition: a randomized study in trauma patients. JPEN J Parenter Enteral Nutr. 2007;31(2):119-26. https://doi.org/10.1177/ 0148607107031002119.

42. Thibault R, Graf S, Clerc A, Delieuvin N, Heidegger CP, Pichard C. Diarrhoea in the ICU: respective contribution of feeding and antibiotics. Crit Care. 2013;17(4):R153. https://doi.org/10.1186/ cc12832.

43. Elpern EH, Stutz L, Peterson S, Gurka DP, Skipper A. Outcomes associated with enteral tube feedings in a medical intensive care unit. Am J Crit Care. 2004;13(3):221-7.

44. Chang SJ, Huang HH. Diarrhea in enterally fed patients: blame the diet? Curr Opin Clin Nutr Metab Care. 2013;16(5):588-94. https:// doi.org/10.1097/MCO.0b013e328363bcaf.

45. Schneider SM. Microbiota and enteral nutrition. Gastroenterol Clin Biol. 2010;34(Suppl 1):S57-61. https://doi.org/10.1016/s03998320(10)70022-1.

46. Chittawatanarat K, Pokawinpudisnun P, Polbhakdee Y. Mixed fibers diet in surgical ICU septic patients. Asia Pac J Clin Nutr. 2010;19(4):458-64.

47. Spapen H, Diltoer M, Van Malderen C, Opdenacker G, Suys E, Huyghens L. Soluble fiber reduces the incidence of diarrhea in septic patients receiving total enteral nutrition: a prospective, double-blind, randomized, and controlled trial. Clin Nutr. 2001;20(4): 301-5. https://doi.org/10.1054/clnu.2001.0399.

48. Yagmurdur H, Leblebici F. Enteral nutrition preference in critical care: fibre-enriched or fibre-free? Asia Pac J Clin Nutr. 2016;25(4): 740-6. https://doi.org/10.6133/apjcn.122015.12.

49. O'Keefe SJ, Ou J, Delany JP, Curry S, Zoetendal E, Gaskins HR, et al. Effect of fiber supplementation on the microbiota in critically ill patients. World J Gastrointest Pathophysiol. 2011;2(6):138-45. https://doi.org/10.4291/wjgp.v2.i6.138.

50. Boyle RJ, Robins-Browne RM, Tang ML. Probiotic use in clinical practice: what are the risks? Am J Clin Nutr. 2006;83(6):1256-64; quiz 446-7. https://doi.org/10.1093/ajcn/83.6.1256.

51. Keogh JB, Lau CW, Noakes M, Bowen J, Clifton PM. Effects of meals with high soluble fibre, high amylose barley variant on glucose, insulin, satiety and thermic effect of food in healthy lean women. Eur J Clin Nutr. 2007;61(5):597-604. https://doi.org/10. 1038/sj.ejen.1602564.

52. Wierdsma NJ, van Bodegraven AA, Uitdehaag BM, Arjaans W, Savelkoul PH, Kruizenga HM, et al. Fructo-oligosaccharides and fibre in enteral nutrition has a beneficial influence on microbiota and gastrointestinal quality of life. Scand J Gastroenterol. 2009;44(7):804-12. https://doi.org/10.1080/00365520902839675.

53. Manzanares W, Hardy G. The role of prebiotics and synbiotics in critically ill patients. Curr Opin Clin Nutr Metab Care. 2008;11(6): 782-9. https://doi.org/10.1097/MCO.0b013e328312c4f9.

54. Bouhnik Y, Vahedi K, Achour L, Attar A, Salfati J, Pochart P, et al. Short-chain fructo-oligosaccharide administration dosedependently increases fecal bifidobacteria in healthy humans. J Nutr. 1999;129(1):113-6. https://doi.org/10.1093/jn/129.1.113.

55. McFarland LV. Meta-analysis of probiotics for the prevention of antibiotic associated diarrhea and the treatment of Clostridium difficile disease. Am J Gastroenterol. 2006;101(4):812-22. https://doi. org/10.1111/j.1572-0241.2006.00465.x.

56. Sanders ME, Levy DD. The science and regulations of probiotic food and supplement product labeling. Ann N Y Acad Sci. 2011;1219(Suppl 1):E1-e23. https://doi.org/10.1111/j.1749-6632. 2010.05956.x.

57. Salminen MK, Tynkkynen S, Rautelin H, Poussa T, Saxelin M, Ristola M, et al. The efficacy and safety of probiotic Lactobacillus rhamnosus GG on prolonged, noninfectious diarrhea in HIV 
Patients on antiretroviral therapy: a randomized, placebo-controlled, crossover study. HIV Clin Trials. 2004;5(4):183-91. https://doi.org/10.1310/6f83-n39q-9ppp-lmvv.

58. Preidis GA, Versalovic J. Targeting the human microbiome with antibiotics, probiotics, and prebiotics: gastroenterology enters the metagenomics era. Gastroenterology. 2009;136(6):2015-31.

59. Bengmark S. Synbiotics and the mucosal barrier in critically ill patients. Curr Opin Gastroenterol. 2005;21(6):712-6.

60. Siempos II, Ntaidou TK, Falagas ME. Impact of the administration of probiotics on the incidence of ventilator-associated pneumonia: a meta-analysis of randomized controlled trials. Crit Care Med. $2010 ; 38(3): 954-62$. https://doi.org/10.1097/CCM. $0 \mathrm{~b} 013 \mathrm{e} 3181 \mathrm{c} 8 \mathrm{fe} 4 \mathrm{~b}$.

61. Sawas T, Al Halabi S, Hernaez R, Carey WD, Cho WK. Patients Receiving Prebiotics and Probiotics Before Liver Transplantation Develop Fewer Infections Than Controls: A Systematic Review and Meta-Analysis. Clin Gastroenterol Hepatol. 2015;13(9):156774.e3; quiz e143-4. https://doi.org/10.1016/j.cgh.2015.05.027.

62. Besselink MG, Timmerman HM, Buskens E, Nieuwenhuijs VB, Akkermans LM, Gooszen HG. Probiotic prophylaxis in patients with predicted severe acute pancreatitis (PROPATRIA): design and rationale of a double-blind, placebo-controlled randomised multicenter trial [ISRCTN38327949]. BMC Surg. 2004;4:12. https://doi.org/10.1186/1471-2482-4-12.

63. Caparros T, Lopez J, Grau T. Early enteral nutrition in critically ill patients with a high-protein diet enriched with arginine, fiber, and antioxidants compared with a standard high-protein diet. The effect on nosocomial infections and outcome. JPEN J Parenter Enteral Nutr. 2001;25(6):299-308; discussion -9. https://doi.org/10.1177/ 0148607101025006299 .

64. (AHRQ) AHCRaQ. Clinical Guidelines and Recommendations. Rockville: Agency for Healthcare Research and Quality; 2018. http://www.ahrq.gov/professionals/clinicians-providers/guidelinesrecommendations/index.html

65. Grabitske HA, Slavin JL. Low-digestible carbohydrates in practice. J Am Diet Assoc. 2008;108(10):1677-81. https://doi.org/10.1016/j. jada.2008.07.010.
66. McIvor AC, Meguid MM, Curtas S, Warren J, Kaplan DS. Intestinal obstruction from cecal bezoar; a complication of fibercontaining tube feedings. Nutrition. 1990;6(1):115-7.

67. Vanderbeek PB, Fasano C, O'Malley G, Hornstein J. Esophageal obstruction from a hygroscopic pharmacobezoar containing glucomannan. Clin Toxicol (Phila). 2007;45(1):80-2.

68. Simakachorn N, Bibiloni R, Yimyaem P, Tongpenyai Y, Varavithaya W, Grathwohl D, et al. Tolerance, safety, and effect on the faecal microbiota of an enteral formula supplemented with pre- and probiotics in critically ill children. J Pediatr Gastroenterol Nutr. 2011;53(2):174-81. https://doi.org/10.1097/MPG. 0b013e318216flec.

69. McClave SA, Taylor BE, Martindale RG, Warren MM, Johnson DR, Braunschweig C, et al. Guidelines for the Provision and Assessment of Nutrition Support Therapy in the Adult Critically Ill Patient: Society of Critical Care Medicine (SCCM) and American Society for Parenteral and Enteral Nutrition (A.S.P.E.N.). JPEN J Parenter Enteral Nutr. 2016;40(2):159-211. https://doi.org/10.1177/0148607115621863.

70. Heyland DK, Dhaliwal R, Drover JW, Gramlich L, Dodek P. Canadian clinical practice guidelines for nutrition support in mechanically ventilated, critically ill adult patients. JPEN J Parenter Enteral Nutr. 2003;27(5):355-73. https://doi.org/10.1177/ 0148607103027005355.

71. Kreymann KG, Berger MM, Deutz NE, Hiesmayr M, Jolliet P, Kazandjiev G, et al. ESPEN Guidelines on Enteral Nutrition: Intensive care. Clin Nutr. 2006;25(2):210-23. https://doi.org/10. 1016/j.clnu.2006.01.021.

72. Singer P, Blaser AR, Berger MM, Alhazzani W, Calder PC, Casaer MP, et al. ESPEN guideline on clinical nutrition in the intensive care unit. Clin Nutr. 2019;38(1):48-79. https://doi.org/10.1016/j. clnu.2018.08.037.

Publisher's Note Springer Nature remains neutral with regard to jurisdictional claims in published maps and institutional affiliations. 